\title{
INTERPRETATION OF HISTOGRAMS AND ITS CORRELATION WITH PERIPHERAL SMEAR FINDINGS
}

\author{
Ashish Gupta1, Pragya Gupta², V. M. Bhaghat ${ }^{3}$ \\ ${ }^{1}$ Consultant, Department of Haematopathology and Molecular Biology, Bhagwan Mahaveer Cancer Hospital, Jaipur, Rajasthan. \\ ${ }^{2}$ Senior Resident, Department of Pathology, Bhagwan Mahaveer Cancer Hospital, Jaipur, Rajasthan. \\ ${ }^{3}$ Additional Professor, Department of Pathology, Government Medical College, Surat, Gujarat.
}

\section{ABSTRACT}

\section{BACKGROUND}

The blood cell counters have evolved over a decade from 3 parts to 5 parts and presently even 7 parts differential cell counters have stepped into the haematopathology world. These cell counters generate histograms, which are a graphic representation of different population cell types and are a neglected piece of information by haematopathologist. The present study to the best of our knowledge is first of its kind in Indian scenario, which throws light on indispensable information generated by the histogram flags and their respective concurrence with peripheral smear findings.

\section{MATERIALS AND METHODS}

The study is conducted on haematology histograms for RBC, WBC and platelets generated by 3-part cell counter by Sysmex KX-21 and their degree of concurrence and non-concurrence with (Giemsa stained) peripheral smear findings respectively. Study DesignIt is a descriptive study of 100 cases being studied at central clinical laboratory, Department of Pathology, Government Medical College, Surat.

\section{RESULTS}

A 100\% concurrence was found between RU, PU, WU and F1, F2, F3 flags and their peripheral smear findings. The degree of nonconcurrence varied from $10.6 \%$ (T2 flag) to $20 \%$ (WL flag).

\section{CONCLUSION}

The principle causes of non-concurrence as concluded by the study are predominantly preanalytical errors as EDTA induced platelet clumps and high background electrical noise leading to generation of erroneous flags. The other causes include activated cells (Lymphocytes), large giant platelets or polychromatophilic erythrocytes.

\section{KEYWORDS}

Interpretation, Histogram, Correlation, Peripheral Smear, Findings.

HOW TO CITE THIS ARTICLE: Gupta A, Gupta P, Bhaghat VM. Interpretation of histograms and its correlation with peripheral smear findings. J. Evolution Med. Dent. Sci. 2017;6(60):4417-4420, DOI: 10.14260/Jemds/2017/955

\section{BACKGROUND}

During the last decade, blood count analysers have undergone a formidable technological evolution owing to an increasing use of fully automated haematology analysers by a growing number of haematology laboratories. The new generation analysers produce various histograms, which give ample information even before blood smear is examined.

Haematology histogram is a graphic representation of different population cell types as haematology analysers count and size thousands of cells to produce a histogram.(1) Haematology histograms are a neglected piece of information generated by most haematology analysers.(1)

An important function of the flag generated by three part differential analyser is the demonstration of abnormality before the blood smear is examined. With regard to red cell and platelet curves, none of these histograms are meant to replace the traditional manual review of peripheral smears. Rather, they should be used to select those peripheral smears

Financial or Other, Competing Interest: None.

Submission 23-05-2017, Peer Review 14-07-2017,

Acceptance 20-07-2017, Published 27-07-2017.

Corresponding Author:

Dr. Ashish Gupta,

Flat Number 203, Plot number C-103,

Sona Avinash Enclave, Savitri Path,

Bapu Nagar, Jaipur, Rajasthan-302015.

E-mail: ashishgupta.path@gmail.com

DOI: $10.14260 /$ jemds/2017/955 which require manual review and they help direct attention to certain subtle abnormalities, which might go undetected by traditional eye count method.(1)

\section{MATERIALS AND METHODS}

This study was performed in year 2010 at central clinical laboratory, New Civil Hospital, Surat, India. The total number of cases studied was 100 . All the cases were indoor patients, as their history and followup can be taken easily.

The study was performed on Sysmex KX-21 (3 part cell differentiation counter). Interpretation of histograms was done in all the cases, after which a concurrence with their peripheral smear was done to find out the percentage of concurrence, various causes of flags and possible causes of non-concurrence.

\section{Study Design}

It is a descriptive study of 100 cases being performed on Sysmex KX-21 (3-part cell differentiation counter).

\section{RESULTS}

The total number of studied cases was 100 , out of which 50 cases were studied for interpretation of RBC histograms, 50 cases for WBC histograms and 55 cases focused on platelet histograms and its concurrence with peripheral smear respectively.

The RBC flags analysed were RL and RU flags generated by Sysmex 21. 
Out of 50 cases, $70 \%$ showed RL $(n=35)$ and $30 \%$ showed $\mathrm{RU}(\mathrm{n}=15)$. On further evaluation of the peripheral smear, $100 \%$ concurrence was seen in RU cases, out of which 11 cases had presence of nRBCs (Figure 1) and 4 cases had agglutination (Figure 1); 85.7\% $(n=35)$ concurrence was seen in RL cases where platelet clumps was seen in 12 cases (Fig. 2) followed by 8 cases of RBC fragments (Fig. 2), 7 cases of large platelets and 3 of micro erythrocytes; $14.3 \%$ among RL flag $(n=35)$ did not show any cause of the peripheral smear, so the cause was thought to be the background noise.

The WBC flags which were analysed in this study included WL, WU, T1, T2 and F1, F2, F3 flags generated by Sysmex 21.

Out of 50 cases T2 flags were seen in 19 samples, T1 flags were seen in 9 samples and F1, F2, F3, WL, WU flags in 22 samples.

Among T1 flag, most common cause was large myeloid precursor in 4 samples, lymphoblast (Figure 5A) and myeloblast in 2 samples each. In T2 flag, most common cause was myeloblast (Figure 5B) in 7 samples, platelet aggregates in 4 samples and myeloblast, giant platelet and P. falciparum rings in 2 samples each. WL flagging was caused due to platelet aggregates (Figure 3) in 4 samples and WU in 3 samples due to abnormally large myeloid precursors. Analogous to this F1, F2, F3 flagging is described in Table No. 1 with their causes.

Summary of various flags with their causes of concurrence and non-concurrence is described in Table No. 1 and Table No. 2 respectively. Out of 55 cases, PU flags were seen in samples $12.7 \%(n=7)$ and PL flag was seen in $38.1 \%$ samples $(n=21)$ and platelet aggregates were seen in $49.09 \%$ samples $(n=27)$. In this, $100 \%$ concurrence was seen in PU flag $(n=7)$ and the causes of PU flags were the presence of microcytes in 3 samples, fragmented RBCs in 2 samples and Giant platelets in 2 samples; $80.9 \%$ concurrence was seen in PL flags $(n=21)$. The causes of PL flags were fragmented RBCs in 8 samples, small sized platelets in 7 samples and microcytes in 2 samples consequently. Here, the cause of nonconcurrence was pre-analytical error of high background electrical noise producing the PL flags in $19.04 \%(n=4)$.

$85.18 \%$ concurrence was seen in Platelet AG flag $(n=27)$ when coagulated blood sample was run, but on peripheral smear no platelet aggregates were found.

\begin{tabular}{|c|c|c|}
\hline Flag & Cause on P/S & $\begin{array}{c}\text { No. of } \\
\text { Cases in } \\
\text { Concurrence }\end{array}$ \\
\hline RU & Nucleated RBC & 11 \\
\hline RU & RBC agglutination & 4 \\
\hline RL & Platelet clumps & 12 \\
\hline RL & RBC fragments & 8 \\
\hline RL & Large platelets & 7 \\
\hline RL & Micro Erythrocytes & 3 \\
\hline F1, F2 & $\begin{array}{c}\text { Inappropriate small } \\
\text { and } \\
\text { middle cell } \\
\text { differentiation }\end{array}$ & 4 \\
\hline F1, F2, F3 & $\begin{array}{c}\text { Inappropriate small, } \\
\text { middle } \\
\text { and large cell } \\
\text { differentiation }\end{array}$ & \\
\hline \multicolumn{2}{|c|}{} \\
\hline
\end{tabular}

\begin{tabular}{|c|c|c|}
\hline F2, F3 & $\begin{array}{c}\text { Inappropriate middle } \\
\text { and large cell } \\
\text { differentiation } \\
\end{array}$ & 4 \\
\hline $\begin{array}{c}\text { Peak in large cell } \\
\text { area }\end{array}$ & Neutrophilia & 6 \\
\hline $\begin{array}{c}\text { Peak in middle } \\
\text { cell area }\end{array}$ & Eosinophilia & 6 \\
\hline $\begin{array}{l}\text { Peak in small } \\
\text { cell area }\end{array}$ & Lymphocytosis & 6 \\
\hline $\mathrm{T} 1$ & $\begin{array}{c}\text { Large myeloid } \\
\text { precursors }\end{array}$ & 4 \\
\hline $\mathrm{T} 1$ & Lymphoblast & 2 \\
\hline $\mathrm{T} 1$ & Myeloblast & 2 \\
\hline $\mathrm{T} 2$ & Lymphoblast & 7 \\
\hline $\mathrm{T} 2$ & Myeloblast & 2 \\
\hline $\mathrm{T} 2$ & Platelet aggregates & 4 \\
\hline $\mathrm{T} 2$ & Giant platelets & 2 \\
\hline $\mathrm{T} 2$ & P. falci rings & 2 \\
\hline WL & Platelet aggregates & 4 \\
\hline WU & $\begin{array}{l}\text { Abnormally large } \\
\text { myeloid cells }\end{array}$ & 3 \\
\hline $\mathrm{PU}$ & Microcytes & 3 \\
\hline $\mathrm{PU}$ & Fragmented RBCs & 2 \\
\hline $\mathrm{PU}$ & Giant platelet & 2 \\
\hline PL & Fragmented RBCs & 8 \\
\hline PL & Small sized platelets & 7 \\
\hline PL & Microcytes & 2 \\
\hline $\mathrm{AG}$ & $\begin{array}{c}\text { Platelet aggregates on } \\
\text { P/S }\end{array}$ & 23 \\
\hline \multicolumn{3}{|c|}{$\begin{array}{c}\text { Table 1. Summary of various Flags seen in Histogram } \\
\text { and their Respective Causes on Peripheral Smear } \\
\text { with Number of Cases being Consonant }\end{array}$} \\
\hline
\end{tabular}

\begin{tabular}{|c|c|c|c|}
\hline Flag & $\begin{array}{c}\text { Concurrence } \\
(\%)\end{array}$ & \begin{tabular}{|c|} 
Non- \\
Concurrence \\
$(\%)$
\end{tabular} & $\begin{array}{l}\text { Cause of Non- } \\
\text { Concurrence }\end{array}$ \\
\hline $\mathrm{RU}$ & 100 & - & \\
\hline RL & 85.7 & 14.3 & $\begin{array}{l}\text { High background } \\
\text { electrical noise }\end{array}$ \\
\hline $\mathrm{PU}$ & 100 & - & \\
\hline PL & 80.9 & 19.1 & $\begin{array}{c}\text { High background } \\
\text { electrical noise }\end{array}$ \\
\hline $\begin{array}{c}\text { Platelet } \\
\text { aggregation }\end{array}$ & 85.19 & 14.8 & $\begin{array}{c}\text { Coagulated } \\
\text { blood sample }\end{array}$ \\
\hline $\mathrm{T} 1$ & 88.88 & 11.11 & $\begin{array}{c}\text { Large dense } \\
\text { platelets }\end{array}$ \\
\hline $\mathrm{T} 2$ & 89.4 & 10.6 & $\begin{array}{c}\text { Moderate number } \\
\text { of activated } \\
\text { lymphocytes }\end{array}$ \\
\hline WL & 80 & 20 & $\begin{array}{l}\text { Moderate number } \\
\text { of poly- } \\
\text { chromatophilic } \\
\text { cells }\end{array}$ \\
\hline WU & 100 & - & \\
\hline F1, F2, F3 & 100 & - & \\
\hline \multicolumn{4}{|c|}{$\begin{array}{c}\text { Table 2. Summary of various Flags with their Respective } \\
\text { Percentage of Concurrence and Non-Concurrence } \\
\text { with Possible Causes of Non-Concurrence }\end{array}$} \\
\hline
\end{tabular}






Figure 1. Peripheral Smear showing Erythroblast and RBC Agglutination, thus Generating RU Flag in Histogram



Figure 2. Peripheral Smear showing Platelet Clumps, Fragmented RBCs and Microcytes thus producing RL Flag in Histogram



Figure 3. Moderate Number of Target Cells, Nucleated RBCs, Platelet Aggregates and Malarial Parasites causing WL Flag in Histogram



Figure 4. Presence of Band Forms, Immature Granulocytes, Blast and Lyse-Resistant RBCs (Sickled RBCs) causing WU Flag in Histogram

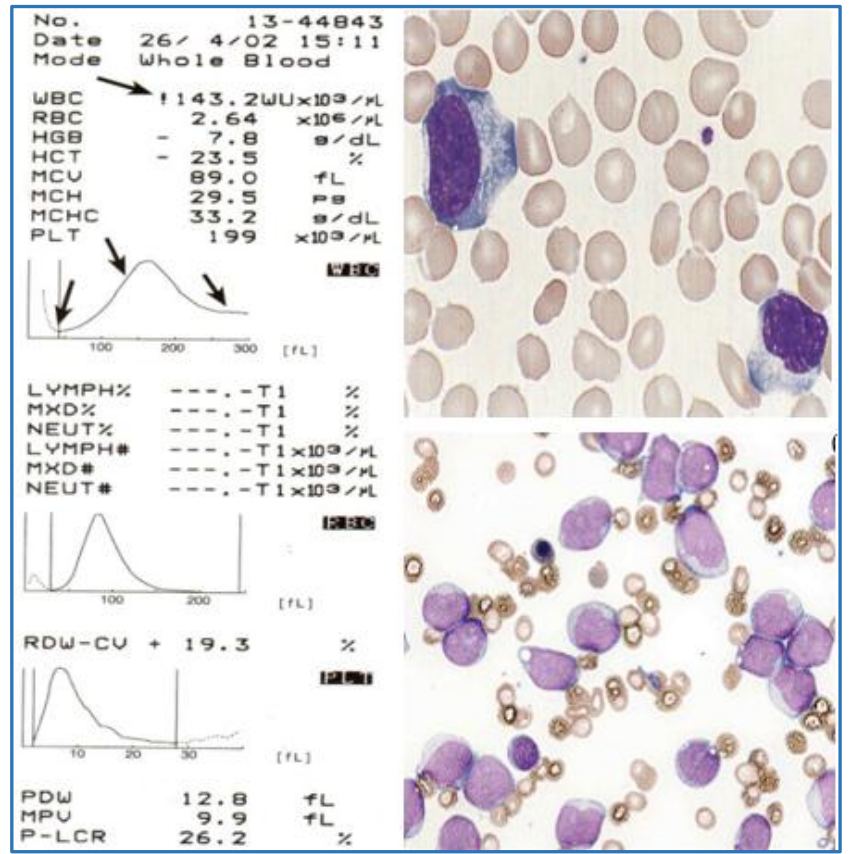

Figure 5A. Presence of Activated Lymphocytes and Lymphoblast causing T1 Flag in Histogram

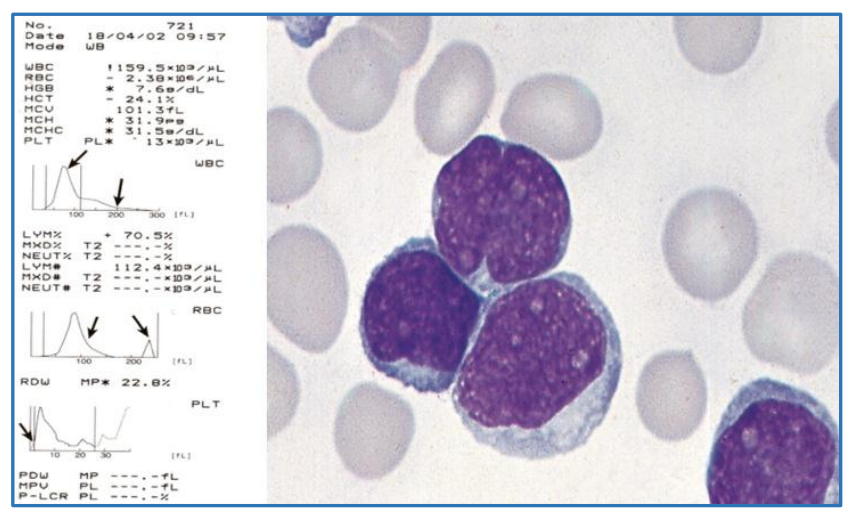

Figure 5B. Presence of Myeloblast causing T2 Flag in Histogram

\section{DISCUSSION}

As histograms are not being so commonly used in day-to-day practice, therefore very little data is available for the comparison and concurrence of this study.

Sysmex KX manual describes in detail the utility and interpretation of these histograms, which can help us understand and read these findings and utilise them in each case.(2)

The manual describes the RBC Histogram error flags and their possible causes. RL flag appears when relative frequency for lower discriminator exceeds the range, which can occur due to effect of noise, RBC morphological changes and platelet agglutination. (2) The same factors of RL flagging was found in our study like platelet clumps, large platelets and RBC fragments (Figure 2). Few samples displayed no concurrence with the peripheral smear due to effect of noise in such cases.

RU flag appears when relative frequency for upper discriminator exceeds the range and the probable cause described was the effect of noise. But in our study, noise did not produce any RBC flags. Instead the most common cause 
was the presence of nRBCs and RBC agglutination (Figure 1) in a few cases.

Similarly, in the Sysmex manual WBC histograms analysis various flagging have been described in detail with eclectic reasoning. One example is WL flagging, which can be caused when there are platelet agglutinations, large platelets, malaria parasite, target cells and nucleated red blood cells (Figure 3). In our study too, platelet aggregates was the most common cause for this flag.(2)

WU flag which was said to be found in haemolysis will be either insufficient or will have the presence of abnormal blood cells. Thus, in our study where abnormally large myeloid precursors were present in maximum cases, this flag was raised too.

Shamsi TS et al(3) also enumerates the causes of WL flag as the presence of nucleated red blood cells, giant platelet, small platelet clumps, moderate number of target cells or polychromatophilic RBCs and malarial parasites. He also described the causes of WU flag (Figure 4) as presence of significant number of abnormal cells (blasts, immature cells), band form of neutrophils, metamyelocyte, immature granulocyte, toxic granulation in neutrophils and lyseresistant RBCs.(3)

The T1 and T2 flagging has been described by several authors. T2 flags are generated when there are blasts, atypical or variant lymphocytes or monocytes, immature lymphocytes, large dense platelets (Figure 5B). T1 flags are triggered when there are immature granulocytes, large activated lymphocytes, blasts (Figure 5A) or large dense platelets. $(4,5,6)$ These factors further correlated well with our study.

Platelet histogram flagging error has been also described in detail in the Sysmex manual,(2) which describes that effect of noise can produce a PL or PU flags which was evident in our study as $19.1 \%$ cases of PL $(n=21)$ were not correlated with the peripheral smear. The reason behind this was no abnormal findings on peripheral smear and generation of flag because of background noise.(2)
Apart from this several other factors like giant platelet, EDTA induced platelet agglutination, coagulation of blood, thrombocytopenia with giant platelets and red cell fragments can all produce PU or AG flag as was found in our study. Furthermore, PU flags were seen in cases of giant platelets, fragmented RBCs and microcytes with an additional confirmation by peripheral smear.

To the best of our knowledge, the detailed study of the concurrence between histograms and its respective peripheral smear finding is one of the rare studies in India. This study is an indispensable insight on the information provided by the histograms and throws light on peripheral smear finding even before smears are examined.

\section{CONCLUSION}

Haematopathology has made a lot of progress due to introduction of five part and seven part counters in conjunction with different principles of working and various flagging pattern, which are usually overlooked by pathologists. Based on our study, we conclude that these flags are an important part of this study and hence should never be ignored.

\section{REFERENCES}

[1] Agarwal MB. Hematology today. 2nd edn. Mumbai: Bombay Hospital Institute of Medical Sciences, 2008.

[2] Sysmex Corporation. Sysmex K4500 Operators Manual. Kobe, Japan: Sysmex corporation; 1994.

[3] Shamsi TS. A practical approach to interpret hematology histograms. ICCBS 2003.

[4] Ward PCJ. The CBS at the turn of the millennium: an overview. Clin Chem 2000;46(8):1215-20.

[5] Walters JG, Garitty PF. Case studies in the new morphology. USA: McGraw Park, II: American Scientific Products; 1987.

[6] Stewart JW. The use of electronic blood cell counters in Routine hematology. Brit J Hematology 1967;13(4):11-8. 